\title{
Evaluation of Analgesic Usage in Pain Management in Bingham University Teaching Hospital
}

\author{
Modupe Iretiola Builders ${ }^{1, *}$, Amos Paul Bassi² \\ ${ }^{1}$ Department of Pharmacology and Therapeutics, College of Medicine and Health Sciences, Bingham University, Jos, Nigeria \\ ${ }^{2}$ Department of Community Medicine, College of Medicine and Health Sciences, Bingham University, Jos, Nigeria
}

Email address:

modupebuilders@yahoo.com (M. I. Builders), bassiap@gmail.com (A. P. Bassi)

${ }^{*}$ Corresponding author

\section{To cite this article:}

Modupe Iretiola Builders, Amos Paul Bassi. Evaluation of Analgesic Usage in Pain Management in Bingham University Teaching Hospital. Science Journal of Clinical Medicine Vol. 6, No. 5, 2017, pp. 86-90. doi: 10.11648/j.sjcm.20170605.15

Received: January 18, 2017; Accepted: February 3, 2017; Published: October 24, 2017

\begin{abstract}
Inappropriate analgesic prescriptions is associated with poor management of pain leading to low recovery, high morbidity, increase hospital stay, decrease patient satisfaction, high costs of admission and adverse drug reactions. Therefore, the aim of this study is to assess the analgesic usage by the medical prescribers at the inpatient and outpatient clinic of a teaching hospital. The study was a descriptive cross-sectional analgesic utilization study, the age, sex, the drugs prescribed per patient were recorded and analgesic prescriptions were analyzed by Pearson test and statistical significance was determined at $\mathrm{P}<0.05$. A total of 2920 prescriptions were analyzed, $88.9 \%$ of the patients were prescribed analgesics, $51.9 \%$ were males, majority of them were between 21 to 41 yrs $(30.5 \%)$. Acetaminophen was the most prescribed analgesic (46.1\%), the most prescribed analgesic combination was ketoprofen and ibuprofen (14.4\%), $75.6 \%$ of the patients were placed on analgesic oral dosage forms and majority of these drugs were prescribed in generic names.
\end{abstract}

Keywords: Analgesics, Pain, Patients, Physicians

\section{Introduction}

Pain is an unpleasant emotional situation which causes reduction in living quality and functional situation of the patients associated with increase in the fatigue levels [1] and impairments in daily life activities in working capacity and social interactions [2]. The undesired problems in psychological and social well-being cause by pain [3], have directed both the patients and caregivers to seek for different searches in pain management [4].

Analgesics currently represent the mainstay of pain management, with an array of drugs available, aspirin, acetaminophen, non-steroidal anti-inflammatory drugs (NSAIDs), mixed agonist and antagonists and narcotic analgesics [5]. The choice of analgesic is governed by the severity of pain, the individual needs and the circumstances of the patient [6].

Research has shown that over prescribing, multi-drug prescribing, misuse of drugs, unnecessary expensive drugs and overuse of analgesics and injections are the most common problems of irrational use by health care providers and consumers [7].

These unnecessary prescriptions often results in aggravated side effects and drug interactions leading to chronic renal failure, therefore there is need for continue medical education to ensure appropriate use of these drugs.

\section{Objective}

\subsection{General Objective}

To assess the use of analgesics and the relationship between variables in the management of pain among the patients in a teaching hospital.

\subsection{Specific Objectives}

To determine the pattern of analgesic prescription in this teaching hospital

To identify the association between analgesic usage and study variables in the management of pain 


\section{Materials and Method}

\subsection{Study Setting}

The study was conducted at the pharmacy department of Bingham University Teaching Hospital, Jos, tertiary, missionary health care facility in North central of Nigeria. This is the department where inpatient and outpatient prescriptions are kept and is manned by pharmacists, internees and pharmacist attendants.

\subsection{Ethical Consideration}

Ethical approval was received from the hospital's research ethics committee prior to commencement of the study.

\subsection{Methods}

Inpatient and outpatient prescriptions of Bingham University Teaching Hospital were evaluated for a period of 4 months, January to April 2016. The prescriptions were assessed for age, sex, analgesic drug used, dose, and route of administration and duration of therapy. The information obtained was recorded in data collection form.

\subsection{Data Analysis}

Data were analyzed using Statistical Package for Social Sciences (SPSS) for windows (version 20.0) and Pearson correlation coefficient was used to measure the degree of association between variables. Results are expressed as percentages and values of $P<0.05$ were considered as significant.

\subsection{Limitation of the Study}

This study was limited to collection of data from prescriptions hence pain could not be classified. However, this has provided useful information on the assessment of analgesic usage for pain by the physicians. Another limitation is inability to monitor prescription of combination of anti-ulcer drugs with analgesics.

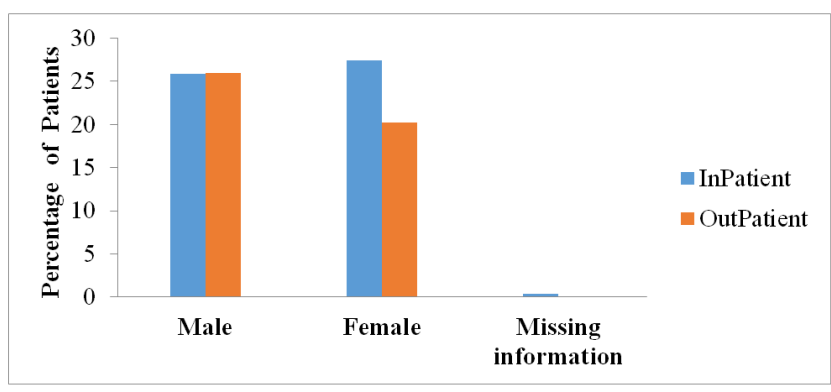

Figure 1. Gender distribution of the patients.

\section{Results}

\subsection{Relationship Between Genders}

Two thousand nine hundred and twenty patients were included in the study, $51.9 \%$ males and $47.6 \%$ females and
$53.3 \%$ of these patients were on admission. There was no significant association between the two gender groups $(\mathrm{P}=$ 0.139 ) as shown in Figure 1.

\subsection{Relationship Between Ages}

Distribution of the patients according to age groups revealed that $30.5 \%$ of the patients were between $21-40$ years while $15.1 \%$ were $41-50$ years and 51 years above. $14.9 \%$ of the patients were less than 10 years. There was a significant association between the two age groups $(\mathrm{P}=0.000)$ as indicated in Figure 2.

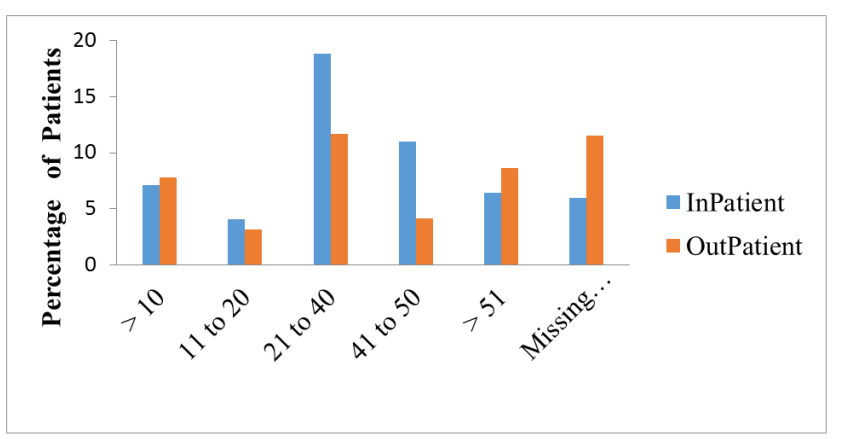

Figure 2. Age distribution of the patients.

\subsection{Prescription of Analgesics}

Figure 3 shows a total of eleven types of analgesics were prescribed for the patients, $94.0 \%$ of the monotherapy analgesics were prescribed for the patients, acetaminophen was the most commonly prescribed analgesic for $25.5 \%$ inpatients and $26.5 \%$ outpatients, followed by ibuprofen for $9.5 \%$ inpatients and $7.1 \%$ outpatients, and $10.7 \%$ inpatients and $1.0 \%$ outpatients received pentazocine. There was a significant association between the analgesic prescription and the patients $(\mathrm{P}=0.000)$

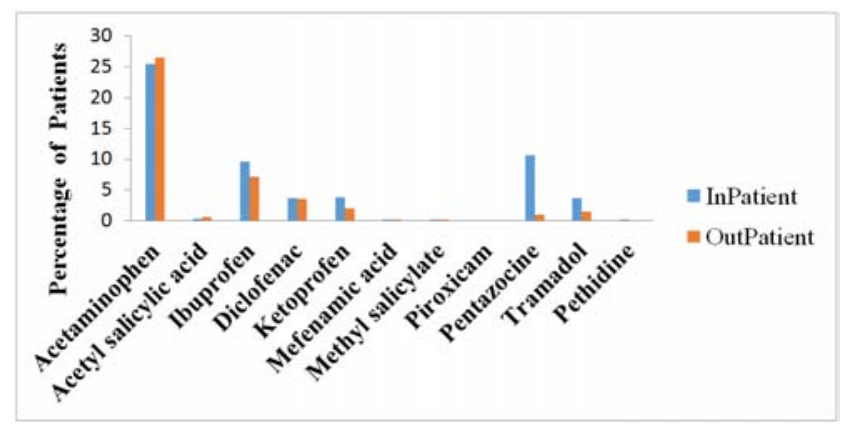

Figure 3. The percencentage use of analgesics.

\subsection{Prescription of Analgesic Combination}

Analgesic combination constituted $6.4 \%$ of these prescriptions. Ketoprofen and Ibuprofen had the highest analgesic combination prescribed for $8.3 \%$ Inpatient and $6.0 \%$ outpatient, followed by ketoprofen and pentazocine prescribed for $9.6 \%$ inpatients and $4.2 \%$ outpatients while $6.6 \%$ and $6.0 \%$ were placed on Ibuprofen and acetaminophen. There was no significant association between 
analgesic combination prescription and the patients $(\mathrm{P}=$ 0.692) (Figure 4).

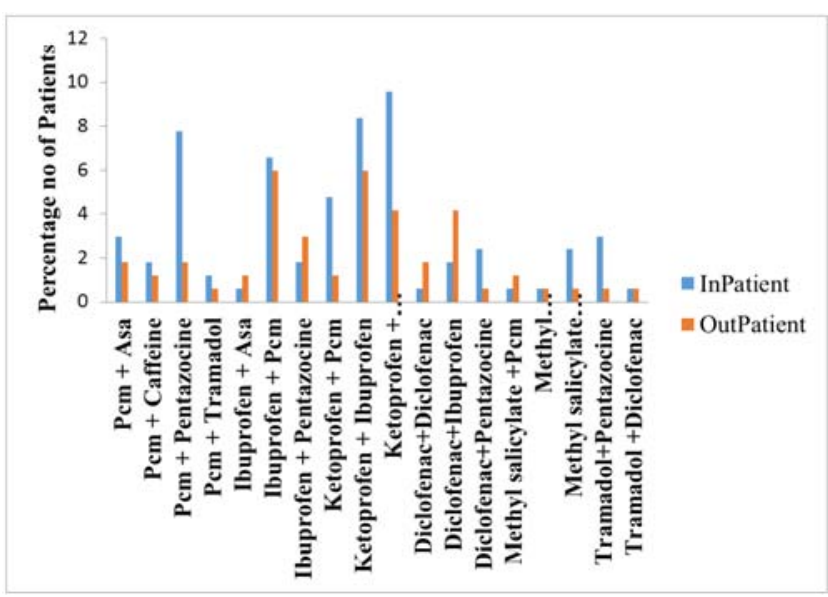

Figure 4. The percentage use of analgesic combination.

\subsection{Analgesic Dosage Forms}

$38.5 \%$ Inpatients and $37.1 \%$ outpatients were prescribed analgesic oral dosage forms, $16.6 \%$ and $6.3 \%$ of the inpatients and outpatients were placed on parenteral analgesics while $0.5 \%$ and $1.0 \%$ were prescribed topical analgesic preparations. There was a significant association between analgesic preparations and the patients $(\mathrm{P}=0.000)$ as indicated in Figure 5.

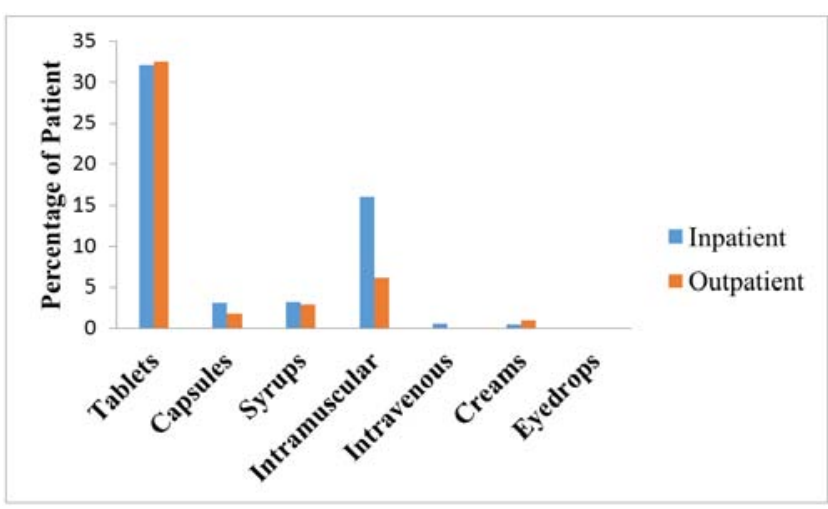

Figure 5. The percentage use of analgesic dosage forms.

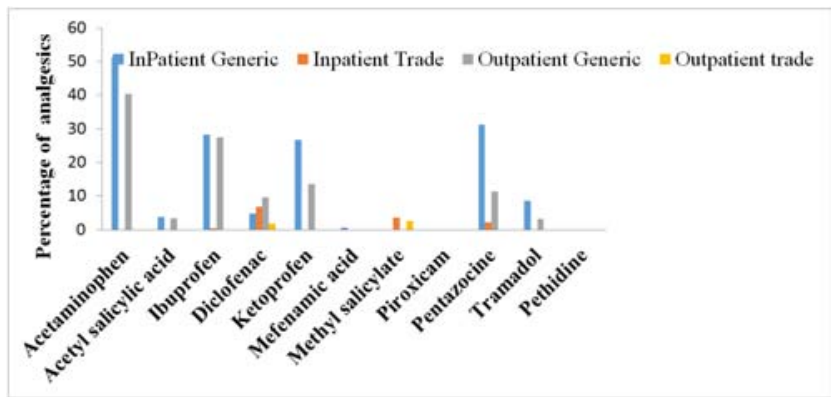

Figure 6. The percentage of analgesics by name.

\subsection{Naming of Analgesics}

Majority of the analgesics, $91.6 \%$ acetaminophen, $50.0 \%$ ketoprofen, $0.2 \%$ piroxicam, $11.8 \%$ tramadol and $0.2 \%$ pethidine were prescribed in generic name for both inpatients and outpatients while $6.5 \%$ of methyl salicylates were prescribed in trade name. There was a significant association between generic name and trade name $(\mathrm{P}=0.000)$ as shown in Figure 6.

\section{Discussion}

In this study, males had more prescriptions than the females, this finding is similar to those obtained in studies carried out in other hospitals where analgesics were more prescribed for males than females [8]. However, the situation is different in many hospitals and this is clearly shown by some studies $[9,10]$, where there were more prescriptions for females than males. Economic factors may also play a role in the health seeking pattern of this group of patients $[11,12]$. Male and female patients were similarly represented and treated for pain; therefore there is no significant association between the two gender groups in the inpatient clinic and outpatient clinic.

This survey identified persons in different demographic groups those in younger age groups, and the elderly, because both rural and urban population of different classes background come daily to this health care facility from various parts of Jos to take treatment of their common diseases. Analgesic prescriptions were more common for adults than children, our study confirms previous studies carried out in clinical settings where many analgesic prescriptions were for the adults $[9,10]$. This finding also corresponds with significant association between ages and patient, this means that the age of patient prescribed analgesic was dependent on patient.

Almost all the patients were prescribed single analgesics ranging from non-narcotic which included acetaminophen, acetylsalicylic acid, ibuprofen, diclofenac, ketoprofen, mefenamic acid, methyl salicylate and piroxicam while pentazocine, tramadol and pethidine were the narcotic analgesics administered to the patients.

The breakdown of the prescriptions showed that acetaminophen was the most frequently used analgesic, the reasons are at the standard dose is safe, choice of drug for mild to moderate pain and lack of major side effects common to other analgesic agents with increase tolerability and acceptability $[9,13]$. Similar observation was made in studies conducted in Nigeria, Ghana and Bangladesh where acetaminophen formed the largest percentage of analgesic prescribed in Hospitals [13, 14].

Ibuprofen, non-steroidal anti-inflammatory drug (NSAID) was the second highest used monotherapy analgesic, this finding is in contrast with the study conducted in some countries $[15,16]$, where diclofenac was one of the most common prescribed drug. Research has also shown that ibuprofen was the most often prescribed NSAID which is similar to our study $[17,18]$.

Among the opioid analgesics prescribed, pentazocine had the highest prescription followed by tramadol and pethidine, 
this may be attributed to the fact that this class of drugs is reserved only for severe pain in order to minimize the issue of tolerance and addiction to them [19]. This low level of narcotic analgesic prescription is in agreement with study conducted by some researchers [10, 13]. Pain relief involves the treatment of the cause of pain as well as treatment of the pain itself as well as assessment of patient individually [20]; this therefore explains the significant association between the analgesic prescriptions and the patients.

Combination of analgesics or 'multimodal analgesics was prescribed for few of these patients, analysis of these prescriptions indicated that the most common combination was two NSAIDs (ketoprofen and Ibuprofen), this may be as a result of superior analgesia at equivalent doses produce by these drugs [21]. However, this combination is not beneficial due to increased risk of serious toxicities such as gastrointestinal (GI) ulceration and bleeding which may be minimized by recommendation of proton pump inhibitors [8, 22]. This does not support the research carried out in some countries [8, 10, 13], where opioid and NSAIDs and NSAID and acetaminophen formed the analgesic combination. Combination of acetylsalicylic acid with other analgesic is as a result of indication for primary prevention of the complications of cardiovascular disease [23], therefore its inclusion in analgesic combination prescription is justifiable. Analgesic usage is dependent on the type of pain, this correlates with insignificant association of analgesic combination prescriptions and patients.

The most frequently used of analgesic route of administration was oral, this mode of administration of analgesic is similar to some physicians [13], where many of the patients were prescribed oral analgesic preparations. The physicians in this hospital therefore conformed to prescribing guidelines for primary care clinicians who state that parenteral analgesics should be reserved for patients with acute pain, they are rarely necessary. Pharmacokinetics and clinical trials of oral analgesics showed that they were effective as injections, with oral medications more cost effective [24, 25]. The significant association between route of analgesic administration and the patients was as a result of severity of pain suffered by the patients which warranted combination of parenteral analgesics with oral analgesic.

Prescription of generic name analgesic dominated this study, the finding of this research is similar to that of many researchers $[10,13]$, where majority of the analgesics were prescribed in generic name. The use of prescription of drugs in generic name provides special importance for rational use of drug with respect to cost, safety and efficacy, this allows the identification of the products by its scientific names [26]. This also permits the prescribers, dispenser and users to choose between many alternative competing in terms of quality, price or convenience [10]. Due to the availability of brand form of methyl salicylate in this teaching hospital, methyl salicylate was not prescribed in generic name for the hospitalized patients; similar observation was observed in
Nigeria where almost all of methyl salicylate was prescribed in branded name [13]. The active ingredient of analgesic drug is determines the naming of analgesic drug, therefore there was a significant correlation between naming of analgesic and composition of analgesic drugs.

\section{Conclusion}

This study indicates analgesic usage pattern by the physicians which comprises appropriate use of these drugs in relation to strength, frequency and duration of therapy, administration of large oral analgesic preparations and high generic naming of drugs as well as high compliance to National Drug Policy and Standard Treatment Guidelines by the prescribers. There is need to organize from time to time continuing education to enlighten the health professionals on the current trend on analgesic use and combination in order to promote and enhance the rational use of analgesics in our health care facilities.

\section{References}

[1] J. E. Kim, M. Dodd, and C. West, "The PRO-SELF Pain control program improves patients knowledge of cancer pain management”, Oncology Nursing Forum, vol. 31, pp. 11371143,2004

[2] S. C, McMillan, M. Tittle, S. Hagan and J. Laughlin, "Management of pain and pain- related symptoms in hospitalized veterans with cancer", Cancer Nursing, vol. 23, pp. 327-336, 2000.

[3] Y. Demir, "Non-Pharmacological therapies in pain management, pain Management-current issues and opinions", Dr. Gabor Racz (Ed.), ISBN: 978-953-307-813-7, InTech, pp. 803- 807, 2012.

[4] R. Evans and A. Rosner, "Alternative in cancer pain treatment: the application of chiropractic care", Seminars in Oncology Nursing, vol. 21, pp. 184-189, 2005.

[5] M. I. Builders and C. N. Aguwa, "Patients attitude towards analgesic usage in Nsukka community", Der Pharmacia Lettre, vol. 4, pp. 641-647, 2012.

[6] M. Nordin, "Self-care techniques for acute episodes of lowback pain", Best Practice and Research Clinical Rheumatology", Vol. 16, pp. 89-101, 2002.

[7] M. I. Builders, "Rational and Irrational use of analgesics: A review”, World J. Pharm Sci, vol. 4, pp. 55-60, June, 2016.

[8] S. Sen and P. Bathini. "Auditing Analgesic Use in Postoperative Setting”, J. Clin. Diag. Res, vol. 9, pp. FC01-FC04, April, 2015.

[9] F. A. Fehintola and A. A. Ganiyu, "Prescriptions involving analgesic drugs at a secondary health facility in Ibadan, Nigeria", Annals of Ibadan Postgraduate Medicine, vol. 6, pp. 34-38, December, 2008.

[10] T. C. Hayas Mohammed, M. Beegum, and P. Perumal, "Prescribing pattern of analgesics in a tertiary care hospital", Int. J. PharmTech Res, vol. 3, pp. 1521-1529, 2011. 
[11] M. I. Builders, E. Ogbole, T. Akande and T. Ogundeko. "Drug utilization study in Bingham University teaching hospital", Donnish J. Med. Med Sci, vol. 2, pp. 72-77, June, 2015.

[12] J. O. Fadare, S. M. Agboola, O. A. Opeke and R. A. Alabi, "Prescription pattern and prevalence of potentially inappropriate medications among elderly patients in a Nigerian rural tertiary hospital", Therapeutics and Clinical Risk Management, vol. 9, pp. 115-120, March, 2013.

[13] A. Kamaldeen, L. M. Omuya, M. A. Buhari, A. O. Saka and M. J Saka. "Evaluation of analgesics usage in pain management among physicians", J. Appl. Pharm Sci, vol. 02, pp. 194-198, January, 2012.

[14] M. I. Builders, J. M. Okonta and C. N. Aguwa. "Prescription patterns of analgesics in a community hospital in Nsukka", J. Pharm Sci. Res, vol. 3, pp. 1593-1598, 2011.

[15] N. B, Bhansali, T. R Gosai, N. K. Dholaria, S. D. Suthar and J. Chacko, " Drug utilization study in post- operative patients in surgical ward of a tertiary hospital attached with a medical college". Der Pharmacia Lettre, vol. 5 pp. 251-57, 2013.

[16] V. Vlahovic-Palcevski, B. Wettermark, and U. Bergman. "Quality of nonsteroidal anti-inflammatory drug prescribing in Croatia (Rijeka) and Sweden (Stockholm)", Eur. J. Clin Pharmacol, vol. 58, pp. 209-214, 2002.

[17] A. D. Paul and C. K. Chauhan. "Study of usage pattern of nonsteroidal anti-inflammatory drugs (NSAIDs) among different practice categories in Indian clinical setting", Eur. J. Clin. Pharmacol, vol. 60, pp. 889-892, 2005.

[18] D. Henry, L. L. Lim, L. A. Garcia Rodriguez, S. Perez
Guttmann, J. L. Carson and M. Griffin, "Variability in risk of gastrointestinal complications with individual nonsteroidal anti-inflammatory drugs: results of a collaborative metaanalysis”, B. M. J vol. 312, pp. 1563-1566, June, 1996.

[19] American pain society, "Principles of analgesic use in the treatment of acute pain and chronic cancer pain", Clin. Pharm, vol. 9, pp. 601-603, 1990.

[20] N. T. Buckley, and R. N. Brogden, "Ketorolac: a review of its pharmacodynamics and pharmacokinetic properties and therapeutic potential", Drug, vol. 39: pp. 86-109, 1990.

[21] World Health Organization, "Cancer pain relief", Geneva, 1986.

[22] M. I. Aguwa, "A hand book of pharmacology and allied health professions" in Analgesics, Onitsha: Nigeria, Africana-FEP. Pub. Ltd, 1998, pp. 72-78.

[23] K. B. Domingo, "Aspirin use for the primary prevention of cardiovascular diseases and colorectal cancer", Annals. Int. Med, vol. 164, pp. 836-845, 2016.

[24] A. Molloy, "Does pethidine still have a place in therapy"? Australian Prescriber, vol. 25, pp. 12-13, 2002.

[25] NSW, "Improving analgesia in hospital emergency departments: optimising use of pethidine Therapeutic Assessment Group (NSW tag)”, pp. 1-6, 2002.

[26] F. Ara and S. A. R, Chowdhury. "Pattern of drug use for under-five children in acute respiratory infections in three selected teaching hospitals in Dhaka city", Bangladesh J. Physiol Pharmacol, vol. 17 pp. 33-36, 2001. 